\title{
WHEN SITTING BECOMES SPORT: LIFE STORIES IN SITTING VOLLEYBALL
}

\author{
Sidiropoulos Charalampos*(a), Carla Filomena Silva ${ }^{(\mathrm{b})}$, Martin Kudlacek ${ }^{(\mathrm{c})}$ \\ (a) Katholieke Universiteit of Leuven, Faculty of Kinesiology and Rehabilitation Sciences \\ (Belgium) \\ (b) Nottingham Trent University (UK) \\ (c) Palacký University of Olomouc, Faculty of Physical Culture (Czech Republic)
}

*Corresponding author (sidirocd@gmail.com)

\begin{abstract}
Results of recent studies support a growing literature which indicates that exercise and physical activity are associated with better quality of life and health outcomes. The purpose of the present qualitative study is to gain a deeper insight into how sitting volleyball players perceive the impact of the sport on their lives. So far, the research in the field of disability and sport has tended to focus on ideological approaches rather than empiricism. Thus, the present study explores how the participants experience their disability and their involvement in sport. The research was conducted with a group of 5 male sitting volleyball players (aged 32 to 61 years old) in Athens, Greece. Data were collected primarily through audio-recorded, semi-structured in-depth interviews and enriched with participant observation field notes. Data was analysed following an Interpretative Phenomenological Analysis (IPA) as the aim of the research was to capture the players' perceptions of their participation in sitting volleyball.
\end{abstract}

Keywords: phenomenology, sitting volleyball, IPA, narrative approach

\section{INTRODUCTION}

Although the original purpose of disability sport was rehabilitation, it has gradually expanded to other forms such as competitive sport, with athletes facing both negative and positive consequences (Vute, 2009). So, the term disability sport refers to sports that have been modified or specifically designed for people with disabilities and sitting volleyball is one of them. According to Vute (2009); "challenging persons with disabilities to try out new activities like volleyball can be a great way to motivate them (p. 10). Thus, the aim of this research is to gain a deeper understanding of how sitting volleyball players perceive the effects of the sport on their lives. A considerable amount of literature has been published on the psychological effects of disability (Hays et al. 1995, Michalko and Tichkovsky, 2009, Beekman et al. 1997). According to Hays et al. (1995), depression, uniquely associated with impairment of wellbeing and functioning, was comparable to or worse than that uniquely associated with major chronic medical conditions. 'Disability' can be 
described as the difficulties experienced in performing necessary activities of daily living due to physical or mental health impairments. Beekman et al. (1997) stated that functional limitations refer to personal capabilities, whereas Michalko and Tichkovsky (2009) made use of the social model of disability, the latter arguing that limitations refer to actual behavior that is evaluated relative to environmental demands. Therefore, subjective well-being may be expected to be relatively independent of changes in physical health in later life (Beekman et al., 1997). Taking these into consideration, the research question of the present study is formulated as "How do sitting volleyball players perceive the impact of the sport on their lives?" As the purpose of the study is to gain a deeper insight into how SV players perceive the impact of the sport on their lives, the expectation of the study is to provide useful information on how this sport affects people's lives and in what ways this takes place.

Research carried out so far does not adequately cover the field of sitting volleyball; the majority of recent studies are quantitative measuring defensive performances (Ibrahim, 2010), scoring skills (Vute, 1999), the effects of different intensity training on some blood variables (Ibrahim, 2010) or studies focused on training-specific injuries (Katalin, 2008). The results that Ibrahim (2010) presented are of great interest as it was proved that weight training sessions had a positive impact on muscle strength of the upper extremities and defensive performances in physically disabled volleyball players (amputees). A detailed study on scoring skills performance by Vute (1999) is a reliable tool for coaches and trainers indicating the structures of different elements in sitting volleyball and guiding to what can be considered as the most useful scoring elements. Moving to more psycho social studies, one can easily see that the evidence available is rather insufficient. A comparative study on mental health between sitting volleyball athletes and the average disabled was conducted by $\mathrm{Fu}$ (2005), demonstrating that "psychological fitness of sitting volleyball athletes is superior to that of their counterparts". Also, physical activity (sitting volleyball) proved to have a positive impact on the psychological health of those involved in it. Additional evidence shows that sitting volleyball improved the levels of psychological health in sitting volleyball male athletes (Gao \& Gao, 2007). Taking into consideration that there is no sufficient amount of philosophical inquiry in the field of adapted physical activity (Reid, 2003), the present study aims to provide useful material for future qualitative research.

\section{METHODS}

The present phenomenological study follows a qualitative design with the researcher being part of the group when possible (participant observation). Field notes are used to enrich data and understand the fluctuations of human behavior. Mulhall, (2003), Clifford and Marcus (1986), and Van Maanen (1988) state the importance of field notes and unstructured observations in qualitative research. Ethnographic field notes are used to interpret how people behave, interact, dress or move in the space, reinforcing the use of dialogue by filtering through what the researcher observes reflecting on his/her own experiences (Mulhall, 2003). The primary instrument in qualitative research is the researcher. Thus, the entire design of the research was filtered through the researcher's subjectivity and the variety of interpretations that a single incident may have.

\section{Sampling procedure}

To strengthen the study, a purposeful sampling strategy built upon inclusion criteria was followed. The study was conducted on sitting 
volleyball players of the professional club "Triptolemos" in Athens, Greece. The participants that cooperated voluntarily for this study were 5 male, sitting volleyball athletes aged between 32 to 61 years old. Four of the participants were Greek, Caucasian and coming from different parts of the social and economic spectrum in Greece. The fifth participant was African, originating from Burundi. The only actual inclusion criterion was that the subjects were involved at least for one year with SV as amateur or professional athletes. The sampling procedure took place in Athens, Greece. Although 5 players is a small sample size, data was enriched by a second (advanced) set of interviews to ensure the validity of the study. For ethical reasons and to ensure anonymity, pseudonyms were used for each participant.

\section{Interviews}

"Narratives do not spring from the minds of individuals but are social creations" (Smith \& Sparks, 2005, p. 1097). Narrators articulate their stories based on the way they interpret their feelings. It is of great importance for this research to underline the words and phrases the athletes use to express their emotions. In qualitative interviews, social scientists investigate human experience and they attempt to gain a deeper insight into the world from the subject's point of view. They try to unfold the meaning of their subjects' lived world. The main characteristic of qualitative interviews is that they give voice to common people and allow them to speak freely and express their opinions and feelings without pre-identified frameworks and with tolerance to sensitive issues. When qualitative interviews came into general use in the social sciences in the 1970s, they were often seen as a progressive dialogical form of research, the answer to "the harsh manipulation of behaviorist experiments" (Kvale, 2006, p. 481). In contrast to such extreme situations, investigators and subjects adopted a gentle, non-directive approach which led to authentic personal relationships between them. In the present research project, the researcher ensured the creation of a similar environment before moving on with the interviews. Building trust through personal relationships is not easy to achieve (Kvale, 2006), but as Miller et al. (2002) point out, a researcher with careful management of his/her appearance can easily build trust between him/her and the potential interviewees. Kvale (2006) also stresses the importance of the "asymmetrical power relationship of an interview" (p. 481). Most of the times, conventional interviews are conducted between a reporter and the "subject", which is considered able to reveal crucial or interesting information. So the relationship which evolves during these interviews leads to a non-balanced situation where the reporter is asking and the interlocutor is responding. The reporter is slowly building a conversation with a purpose. But in qualitative interviewing the researcher is trying to create an atmosphere of mutual interest on the discussed subject and this is how the term "interview dialogue" was invented (Kvale, 2006).

\section{Data collection}

Data collection was carried out over a two month period in Athens, Greece, starting in the second week of January, 2015 and finishing at the end of February, 2015. Two sets of semistructured interviews divided into first (introductory) and second (advanced) part were conducted. Additional data sources were field notes, personal accounts retrieved through the interviews as well as pictures of the whole process.(what process? Be more precise)

\section{Data analysis}

Data was translated, transcribed and analyzed using Interpretative Phenomenological 
Analysis (IPA) following the guidelines as described in Smith and Osborn's work (2007). IPA aims to "explore in detail how participants are making sense of their personal and social world, and the main currency for an IPA study is the meanings particular experiences, events and states hold for participants" (Smith \& Osborn, 2007 p.53). Furthermore, IPA emphasizes the dynamic role that the researcher plays in this process, trying to get close to the participant's personal world and capture the insider's perspective although this is difficult to be achieved directly or completely. Smith and Osborn (2007) refer to IPA as a two-stage interpretation process where participants are trying to make sense of their world and the researcher is trying to understand how the participants are trying to make sense of their world. This chain of connections between people's storytelling and their thinking or emotional state makes the researcher realize how complicated this situation is and how people are sometimes struggling to put their feelings into words. The purpose of this study is to help understand how SV athletes refer to the impact of sitting volleyball on their lives. IPA is believed to be an appropriate method to explore the insider's perspective by interpreting what people think and drawing conclusions from their detailed narrations on this issue. IPA, according to Osborn and Smith (2006), is used to explain in depth that the words used by the participants to describe a phenomenon can give valuable information about the phenomenon itself. In a methodological framework, an IPA study is considered as the product of a reciprocal engagement between researchers and participants (Osborn \& Smith, 2006), while involving a detailed approach and analysis of the accounts produced by a comparatively small sample size and aims to provide a conceptual analysis upon the way people make sense of their experiences (Larkin et al., 2006). Existing literature reveals several studies using IPA and the majority of them is pointing out a four-step analysis process (Smith \& Osborn, 2007; Smith, 2004; Cope, 2011). In the present study IPA analysis, as described in Smith and Osborn's work (2007), helped to make better sense of how sitting volleyball players perceive the impact of the sport on their lives. The process of analyzing data was divided into four basic steps: 1) Detailed reading of each case; initial notes coming from the text and the field notes were annotated in the left margin. 2) These notes were translated into emergent themes using the right margin to write them down. 3) Clustering of themes and making convergences between them. 4) Creation of a master table of themes for the group of five participants using data from the total number of interviews (Table 1). The master, superordinate themes were derived from a detailed cross checking procedure between the transcripts taken from each interview (Table 1). 
Table 1. Master table of emerging themes

\begin{tabular}{|c|c|c|c|c|c|c|}
\hline & & Tom & Mark & Martin & Paul & Roger \\
\hline & Themes and subthemes & I. $\mathrm{n}+$ P. $\mathrm{n} *$ & I. $n+P . n *$ & I. $n+P . n *$ & I. $n+$ P. $n *$ & I. $n+P . n *$ \\
\hline \multirow[t]{7}{*}{1} & Motivational factors & & & & & \\
\hline & $\begin{array}{l}\text { External (money, fame, self- } \\
\text { assertion) }\end{array}$ & & 1.7 & 1.4 & & 1.3 \\
\hline & Internal (passion, competitive spirit) & 1.2 & 1.7 & & & \\
\hline & Weight loss & 2.6 & 2.3 & & 1.7 & 2.5 \\
\hline & Body shape/ image & & 2.4 & 1.5 & $1.7+2.5$ & 2.5 \\
\hline & Physical fitness & 1.8 & & & 1.4 & 2.5 \\
\hline & The invisibility of disability & & 2.5 & 2.4 & & \\
\hline \multirow[t]{7}{*}{2} & Emerging feelings & & & & & \\
\hline & Disappointment/ frustration & 1.4 & 1.6 & & 2.1 & \\
\hline & Pleasure & 1.7 & & 2.1 & 2.6 & 2.3 \\
\hline & Post trauma depression & 2.1 & & 1.1 & & 1.5 \\
\hline & Anxiety/stress & & & 2.1 & 2.2 & 2.6 \\
\hline & Satisfaction & & 1.6 & 2.1 & 2. 6 & 2.3 \\
\hline & Adrenaline & & 1.6 & & 1.3 & 2.1 \\
\hline \multirow[t]{11}{*}{3} & Bodily experience & & & & & \\
\hline & Pain & 2.7 & & $1.2+2.1+2.2$ & $2.1+2.5$ & 2.1 \\
\hline & Whole body involvement/ pain & 1.7 & 2.4 & 2.2 & 2.1 & 2.5 \\
\hline & Physical fitness & 1.8 & 2.6 & & 2.5 & 2.5 \\
\hline & Body change & 1.2 & 2.4 & & 2.3 & 2.5 \\
\hline & Body shape/ image & & & & $1.7+2.5$ & 2.5 \\
\hline & Functional body & & 2.4 & 2.5 & 2.4 & \\
\hline & Physical implications & 1.8 & & & 2.3 & \\
\hline & Neurological implications & 1.8 & & & & \\
\hline & Circulatory benefits & 1.8 & & & 2.4 & \\
\hline & Unbalanced body & 1.8 & 2.3 & & & \\
\hline \multirow[t]{7}{*}{4} & Psychosocial aspect & & & & & \\
\hline & SV as a psychosocial tool & 1.6 & 1.9 & $1.4+1.5+2.4$ & $2.2+2.4$ & $1.5+2.2$ \\
\hline & Positive friends' reactions & 2.5 & & 2.4 & 2.4 & 2.4 \\
\hline & Family's support (Wife's support) & 2.6 & 1.5 & & & \\
\hline & Psychological boost & 2.1 & $\begin{array}{c}2.5+2 . \\
6 \\
\end{array}$ & 2.4 & 2.3 & 2.4 \\
\hline & The invisibility of disability & & $\begin{array}{c}1.9+2 . \\
5\end{array}$ & 2.4 & & \\
\hline & Team spirit & & 1.2 & $1.4+1.5+2.1$ & $1.3+1.4$ & $2.3+2.6$ \\
\hline
\end{tabular}




\section{RESULTS}

The present study aims to describe how SV players perceive the impact of the sport on their lives, gaining a deeper insight into their lives. This is achieved by letting them narrate the interactions between themselves and the sport. Data was analyzed using an interpretative phenomenological perspective and several themes and subthemes emerged from this analysis. Accordingly, four superordinate themes were constructed: bodily experience, psychosocial aspect, emerging feelings and motivational factors.

\section{Bodily experience}

The sub-themes that emerged under the superordinate theme of bodily experience were: pain, physical fitness, body change, whole body involvement, body shapel image, physical implications, neurological implications, circulatory benefits and the unbalanced body. Pain, the first subtheme, proved to be the dominant feeling in everyone's memories. Athletes, who went under the pseudonyms Tom, Mark, Martin, Paul and Roger, talked about pain as an inevitable consequence of playing SV. Four participants referred to painful situations all over their bodies. More specifically, Roger, while trying to recall his first time to play SV, he said "It was like climbing a mountain".

The second subtheme examined under the master theme of bodily experience was physical fitness. Physical fitness is mentioned in several cases by the participants as a motivational factor as well as a positive outcome of their engagement with SV. Tom talked about physical and neurological implications occurring from the loss of a limb. He also described the unbalanced status as an inevitable consequence when one suffers amputation. "The loss of a limb is not a simple thing" he states and is not only limited to loss of mobility and function. Tom placed importance on the physiological, neurological and psychological benefits from his active engagement with SV. "SV is a sport that can keep you fit, especially the abdominals and shoulders," said Roger as well. Ibrahim (2010) supported Roger's statement stating that muscle strength of the arms and upper body is essential in SV and weight lifting has a positive effect on performing defensive and offensive movements. While talking about muscular fitness, all the participants stressed the use of abdominals, shoulders and arm muscles.

Furthermore, the unbalanced body was a common point to discuss with the participants. Mark stressed out the urgent need to stabilize his body weight while playing SV because of the unbalances caused by the use of prosthesis. Relevant to this, the next subtheme, body change and body shape/image seems to be a great influential factor when talking about people with amputations and playing SV. The total of the participants in the present study were born able-bodied and became amputees due to accidents. When disability is not congenital but acquired, according to the participants, the body changes dramatically and they have to adapt to their new body and their new life. This is a challenging procedure and differs from person to person and from body to body. Tom stresses the uniqueness of each body and the individualized approach that each athlete should follow. "There is no formula and it requires time," he said. A different approach was adopted by Mark, who saw the change of body mainly from the muscular point of view. The same perspective was examined by Roger, as mentioned before, when he placed importance on the change that SV training offers to one's upper body muscular system. There seems to be a convergence of views between the two players as they both refer to the same muscle areas that work out and develop through SV training. Roger stressed the excessive use of 
abdominals, trunk, back and chest muscles while Mark underlined the change of body shape as far as the arm and shoulder muscles are concerned. "Only legs change, they do not develop any more, they do not work out any more" Mark mentioned.

A very interesting perspective comes from Paul, who praised SV for changing his body in a beneficial way affecting his everyday life as well. He was asked to mention any differences that he could see on his body after his engagement with SV. "I walk better, it is enough, isn't it?" he said. A better gait pattern is probably the best example of having a more functional body for an amputee. Functional body is the last subtheme that will be examined in the superordinate theme of bodily experience in SV. While reviewing the data taken from interviews and field notes one can realize that in many cases people with amputations do not function as they think they should. "If I could run, I wouldn't go canoeing or play sitting volleyball", says Paul. IPA here throws light on how SV athletes perceive functionality in their lives and at which level they consider their body functional. The questions they were called to respond to focused on whether SV made their body more functional or not. According to Martin, life is not only about sleeping, eating, watching TV and playing video games. "You must do something, anything, just go out and move", he said. He told me that if one is not functioning and moving in his / her everyday life, he/she is not alive.

\section{Psychosocial aspect}

Going through all the narrative accounts of the participants, one can clearly point out the importance they place on the psychological and social perspective of their engagement with the sport. In the present study it was examined how SV can work as a socialization tool for the athletes, giving them also a psychological boost. Further aspects were discussed through the analysis of the subthemes, such as friends' and family's reactions, the wife's support, team spirit and the invisibility of disability.

Is $\mathrm{SV}$ an appropriate activity to improve social life? According to Tom's narration, SV is a "psychosocial tool" for people with disabilities. "Every individual with any acquired disability suffers or suffered from mild or severe depression", says Tom. Depression, according to him is an inevitable consequence of a severe injury and the main characteristic of a post-trauma period; and sports can be the appropriate way to fight against it. As Tom stated, SV is a great way to fight depression because during the games athletes celebrate each point regardless of the final result. In total, during a SV match, one will count more than 50 moments of pleasure and this is essential for his/her psychological health; Tom reported.

Moving on, the socialization aspect appeared to be the most popular point of discussion between the researcher and the participants. All of them talked about SV as a great way to socialize, come in contact with other people, travel, meet cultures and overcome the antisocial effects of having a physical disability.

Another crucial point to underline is the view of disability, in this case the invisibility of disability. The invisibility of disability is used here to explain that the creation of a sporting, functional body leads to better social inclusion according to Mark. He was proud to state "Most of my colleagues don't even know I wear prosthesis". Similar feelings of proudness were revealed while discussing with Martin as well. He underlined the fact that he does not look disabled as a main factor of easier acceptance and inclusion. Examining the present study's findings one can derive that sport makes the body more functional and improves the body image in 
accordance with the commonly accepted standards, increases self-confidence levels and gives a psychological boost to the individuals with disability.

During the second (advanced) interview set, participants were asked to describe their friends' and family's reactions when they announced their potential engagement with SV. The majority of the relevant data showed that the reactions were positive. Two of the participants stressed the positive reaction and support of their wives. Family support seemed to be very important and worked as a motivational factor as well. The wife's role was crucial in Mark's life as well, but in a slightly different way. $\mathrm{He}$ confessed that his wife was the first to motivate him to be patient and keep playing SV after his first contact with the sport, which was disappointing for him. "How can you play volleyball? You miss a leg.", was Martin's best friend's reaction when he announced that he was training with an SV club in Athens. Martin tried to convince his friend by inviting him to join a training session. "What you're doing is very difficult and you deserve congratulations", was his friend's final "verdict". Here we can see how the different themes and subthemes overlap and intersect in the present study. For Martin his friend's approval and admiration was a psychological boost and an extra motive to keep training hard. A smile was stuck on his face while narrating the story. Psychological boost was another subtheme that emerged from the narrations of the participants. Social approval and psychological boost seemed to be two inextricably connected concepts influencing one another.

In the superordinate theme of psychosocial aspect, team spirit played an important role. "It is difficult to put six different personalities in the court", said Roger. The concept of team spirit was something that stemmed out from the participants' narrations without any relevant or triggering questions from my side. "All together...we are a family," said Paul placing importance on the value of friendship. Roger came to support the same view saying that the most important thing for him in creating bonds in a team is the "out of the court" relationships.

\section{Emerging feelings}

The third superordinate theme which resulted from the interpretative phenomenological analysis of the data was emerging feelings. Feelings and emotional situations which stem from the engagement with SV were described by the athletes constructing the following subthemes: disappointment/ frustration, post trauma depression, anxiety/stress, pleasure, satisfaction, adrenaline. Athletes were asked to describe not only how they perceive the impact of SV on their emotional life, but also the feelings occurring during their performance. The majority of the participants attributed the "charm" of the sport to the adrenaline and the speed in motion it offers. Others referred to SV as an amazing workout for the whole body and as an intriguing way to improve their physical fitness and body shape. But not only pleasant feelings emerge from the involvement in SV. While trying to adapt their body and adjust the way they perform in order to meet SV standards, some of the athletes confessed that they went through disappointment and frustration stages. Many of the players reported feelings of frustration while trying to adjust their body in their new life after the accident and to adapt their body to the SV requirements. Tom reports being disappointed and frustrated while trying to adapt his body and find a way to perform in the court.

After a close reading of the data transcripts one can notice that stress was an important factor in describing the athletes' 
experience in SV. Three of the athletes mentioned stressful situations while playing SV. Paul was not the only one to report stress; in Martin's case stress was intense when he played for the first time as well. Furthermore, Roger stated that stress is always present when playing team sports and especially SV. Relevant research material supports the participants' statements that stressful situations occur when athletes perform in major events and, in general, under competition circumstances (Campbell \& Jones, 2002).

Moving on the next subtheme under the superordinate theme of emerging feelings, pleasant feelings were described by the participants as well. In fact, the most popular feeling was pleasure and satisfaction. Four out of five participants reported feelings of pleasure and satisfaction when they were asked to describe how SV affected their lives. Tom stated that SV training sessions were not an obligation but a pleasure for him. Happiness was the dominant feeling in Paul's narration as well. He described feelings of pleasure and psychological boost. "I am reborn" he said several times.

Reviewing the last emerging feeling, adrenaline proved to be the best motivator and one of the most dominant feelings on the court. Mark placed great importance on the feeling of adrenaline. "What new did you find in SV?" I asked him and without thinking he replied: "Adrenaline". Paul and Roger came to support Mark's statement by characterizing adrenaline as the main component and the most charming part of playing SV.

\section{Motivational factors}

During the process, master themes emerged if athletes placed great importance on a factor that was not expected before the questions were asked by the interviewer. Motivational factors constitute such a master theme. These factors were categorized in the following subthemes: External (money, fame etc), internal (passion, competitive spirit), weight loss, body shape, and physical fitness.

Due to the present economic recession in Greece, athletes referred, among others, to the economic factor as something influencing their participation. Income earned by playing sports can be an additional motivational factor of engagement in SV. Roger revealed that he was not motivated to travel 20 kilometers to train in SV without receiving any money at least to cover transport expenses. As he mentioned, lack of financial resources was an additional reason leading to a small number of clubs participating in the championship. "There was no motive," he explained.

External motivational factors also include fame and glory, having supporters and being happy to please the crowds. This was totally absent according to Mark so they had to find internal motivation to keep playing and train in regular basis. Mark named his intrinsic motivation "passion" and "competitive spirit", which bring him in the mood to play SV and enjoy it. "This is the point that sets my adrenaline pumping," he said.

For Paul, weight management and maintenance of body shape results in a better quality of life and he described these variables as the main reason why he is involved in sports. Roger supported Paul's view, underlining the importance of body shape and image as a reason for him to engage in SV and in sports in general. He referred to SV as a tool to help him reduce his body weight after the injury. Weight control has a different value according to Mark. While referring to the unbalanced body, Mark stressed the fact that body weight needs to be stable due to the use of prosthesis. "You must stabilize your weight," he said. Body image seemed to be an important factor for SV athletes, seen both as a motivational factor and as a way to improve 
the invisibility of their disability as well. Overall, athletes preferred not to reflect on their body image. In general, they were only mentioning it in a positive way (Roger, Tom, Paul and Mark) explaining how the sport helped them to develop their body or prevent a possible complication due to their accidents.

To conclude, the data taken from interviews and field notes proved to be rich and served the purpose of the present study. The athletes, revealed, through storytelling, all the possible aspects related to their engagement with SV from their individual sport background to their current sport profile. The themes and subthemes created aimed to cover the whole range of the discussed issues were classified according to their prevalence and importance filtered through the researcher's subjectivity.

\section{DISCUSSION}

"How do SV athletes perceive the impact of the sport on their lives?" was mainly investigated through conversations with athletes. The superordinate themes emerged according to the priorities the athletes set, to their prevalence in their narrations and the interview guide structure. The majority of the players placed importance on the psychosocial impact of SV on their lives and motivational factors of engagement as well. More specifically, Tom stated that depression is an inevitable consequence of having an acquired disability. Existing literature comes to support Tom's statement and confirm that depressive mood is often related with disability (Turner \& Noh, 1988, Bruce, 2000, Bruce et al. 1994, Penninx et al. 1999). According to Turner and Noh (1988), there is a number of studies comparing the psychological health of physically disabled populations with nondisabled individuals. The majority of these studies report a significantly higher level of depression and psychological distress in people with physical disabilities than in ablebodied populations (Turner \& Noh, 1988). Turner and Noh (1998) reported a "relationship between depression and disability" (p. 24), and they stated that "physical disability is associated with dramatically elevated risk for depression regardless of sex, age, education, marital status, area of residence or level of income" (p. 29). Guided through a phenomenological approach, the findings that stemmed from the conversation with the athletes showed that SV can be a powerful tool for someone to fight against depression. Tom referred to $\mathrm{SV}$ as a "psychosocial tool" which can be beneficial for persons with mobility problems. SV was for Tom a way to feel active again, not only physically but socially as well. Happiness and satisfaction were dominant feelings in Tom's narration. He referred to the latter stating that the difference between other disability sports and SV for him is that regardless of the final result; one can have many moments of happiness and satisfaction during a SV game. Mark came to support Tom's statements, saying that $\mathrm{SV}$ is a sport which can bring positive feelings to the surface. Drawing from these, one can conclude that SV can work as an anti-depressive tool for people with mobility limitations, having positive impact both in and out of courts.

The emotional well-being of SV athletes seemed to be of great importance and besides depression, stress was a key-element concerning emerging feelings from SV engagement. Three out of five participants (Paul, Martin and Roger) referred to stressful situations throughout their career, underlining that competitive environments provoke feelings of stress and anxiety. Relevant research material supports the participants' statements that stressful situations occur when athletes perform in major events and, in general, under competition circumstances (Campbell \& Jones, 2002). Although 
conducted with elite male wheelchair basketball athletes, Campbell and Jones's study revealed that sources of stress can be present in both competitive and noncompetitive environments. Focusing on the competitive ones, they present four possible distinct time periods that stress is present: "preevent, prematch, oncourt, and postmatch" (p. 96). "Oncourt" stress was the most dominant in this case as Paul and Roger revealed. Stress in sports can, in many cases, affect the level of performance and cause unexpected results. For instance, in Paul's case stress even made him forget his role in the game: "I didn't know where to go, I was lost", he revealed. According to the participants' narrations, stress was preventing them from having high levels of performance and in many cases was distracting them from their goals, as Paul and Roger stated. But Roger gave another dimension of 'oncourt" stress, talking about the transformation of stress into anger, which results into a desire to fight with teammates and opponents. In general, stress was visible only during their early steps in the field, as three of the athletes (Roger, Paul, Martin) stated that by engaging more and more with the sport, stress was gradually reduced and finally vanished. It is evident that the interactions between the athletes' personalities and the nature of the sport were of vital importance for them in overcoming stress and anxiety.

What motivates individuals with physical disabilities to engage in SV? Which can be the potential motivators for them? In the present study, one of the emerging superordinate themes was the motivational factors of engagement in SV. Discussing the study's findings, socialization and fitness proved to be the dominant reasons of engagement with SV. However, a new dimension was added: body shape/image. Four of the interviewees (Mark, Paul, Roger, Martin) placed importance on the body shape/ image and described it as a motive to start and continue playing SV. There is an amount of existing literature on the reasons that motivate people to get involved in sports and physical activity (Allender et al., 2006, Teixeira et al., 2005, Richard et al., 1997, Koivula, 1999, Protic \& Valkova, 2011, Tangen \& Kudlacek, 2014). Protic and Valkova (2011) conducted a study trying to answer these questions and investigate all the possible correlations between SV and motivation. Coming to support the present study's findings, socialization, entertainment, health, fitness, sport competition and rehabilitation were the motivational factors ranked from most to least important in Protic and Valkova's study (p. 13). Socialization was found to be the most important motivational factor. Most of the studies suggest that weight management and body shape are motivators mostly related with women (Allender et al., 2006, Koivula, 1999, Teixeira et al., 2005) but male SV athletes in this study placed importance on SV as a tool to manage body weight and to maintain or improve their body shape and image. Tom and Mark referred to body weight control as a critical part of their engagement with SV. "Having an amputation is not easy, I must stabilize my weight because of my prosthesis," Mark stated. Discussing Tom's and Mark's statements, one can say that SV had an impact on athletes' everyday life. SV was not only a motivator for them to lose weight, but worked as a means to improve their body shape/ image. "The way they look" proved to be essential for them, especially while exploring the subtheme of the invisibility of disability. The majority of the participants mentioned that their confidence increases when they realize that other people are not aware of their disability. "My colleagues don't know that I have a disability", Mark stated having a smile of proudness on his face. Concluding, this study suggests that $\mathrm{SV}$ created a chain of positive consequences for these athletes 
ranging from improving their fitness levels to developing a more functional body, which results in a better body shape/ image and leads to social approval through the invisibility of their disability.

Athletes reported that SV acted as a means to improve their body functionality and cope with the requirements of everyday life. Paul stated that after his engagement with SV he improved his gait pattern and Tom referred to $\mathrm{SV}$ as a tool to overcome the physiological implications that occurred after his injury. In Paul's case functionality has a subjective meaning: "If I could run I would not play SV", he stated. From a phenomenological point of view, functionality depends on how one is defining it; what normal functioning is (Jespersen \& McNamee 2008). Jespersen and McNamee (2008) referred to functionality stating that "It is true that we can choose to see human beings as complex machines that, in their normal state, function as they should" ( p. 90). Tom talked about the complexity of human bodies as well: "amputations create unbalanced situations in our bodies; it is a multidirectional, complex situation, it's not simple", he stated (interview 1, page 8). Aligned with Jespersen and McNamee, 2008, Tom mentioned that in his case his body had changed the way it functions. Furthermore, he explained that $\mathrm{SV}$ is a sport in which the whole body is involved and there is no use of supportive devices such as wheelchairs, a fact that helps develop a more functional body with positive effects on the psychophysical status of each individual. Another positive dimension of $\mathrm{SV}$ is the feeling of independence that SV offers to athletes as they do not depend on wheelchairs or running blades to improve their performance. Their body is the only tool they have. From a phenomenological point of view, the whole body involvement is interpreted as a state of realization of what their bodies are capable of. The majority of the participants mentioned that they preferred SV to other disability sports because they could work out as many muscle masses as possible and explore their physical capabilities to their maximum.

Overall, SV proved to have a positive impact on the athletes' lives. The players revealed that their everyday life, mood and physical status were inextricably connected with their engagement with SV. All players reported that SV affected their social behavior and their body shape/ image in a positive way. Examined from a phenomenological perspective, the nature of the sport implies that six different personalities should cooperate and work for a common goal. This situation, as described by Roger, can be very unpleasant and requires time in order to make it work properly. This process develops important social interactions between athletes and teaches them to be patient and to accept failure. These social interactions have different dimensions depending on each individual's perspective. For more experienced players such as Mark, it was easier to become part of the group and be popular among his teammates. On the other hand, three participants (Paul, Roger, Martin) confessed that the socialization process was more time and energy consuming for them. This phenomenon is explained by the fact that novice volleyball players are usually struggling to learn the technical part of the sport and this acts as a distractive factor for socialization. Furthermore, according to the athletes' confessions, SV worked as a rehabilitation means for them to keep their body active and overcome the unbalanced situation caused due to their amputations. It is important to mention that four athletes stated that SV helped them to improve their fitness levels, as the whole body participates in the sport, stressing the involvement of the upper body (shoulders, arms and abdominals).

But not only positive outcomes were retrieved from the interviews; feelings of 
disappointment for the current downgrading situation of SV in Greece and the absence of an official championship were the most dominant negative issues that occurred. While reviewing the findings of this study, one can state that the majority of the athletes were not intrinsically motivated to keep playing SV. Lack of financial support and external recognition proved to become barriers to prolonging the engagement with SV for three participants (Paul, Roger and Martin). As a result, athletes reported feelings of frustration and disappointment during their careers, although this was not a dominant feature in their memories.

\section{REFERENCE}

Allender, S., Cowburn, G., \& Foster, C. (2006). Understanding participation in sport and physical activity among children and adults: a review of qualitative studies. Health education research, 21(6), 826835.

Beekman, A. T. F., Deeg, D. J. H., Braam, A. W., Smit, J. H., \& Van Tilburg, W. (1997). Consequences of major and minor depression in later life: a study of disability, well-being and service utilization. Psychological medicine, 27(6), 1397-1409.

Bruce, M. L. (2001). Depression and disability in late life: directions for future research. The American Journal of Geriatric Psychiatry, 9(2), 102-112. DOI: 10.1097/00019442-200105000-00003.

Bruce, M. L., Seeman, T. E., Merrill, S. S., \& Blazer, D. G. (1994). The impact of depressive symptomatology on physical disability: MacArthur Studies of Successful Aging. American Journal of Public Health, 84(11), 1796-1799. DOI: 10.2105/AJPH.84.11.1796.

Campbell, E., \& Jones, G. (2002). Sources of stress experienced by elite male wheelchair basketball players. Adapted Physical Activity Quarterly, 19 (1), 82-99. Clifford, J., \& Marcus, G. E. (Eds.). (1986). Writing culture: the poetics and politics of ethnography: a School of American Research advanced seminar. University of California Press. ISBN: 0-520-05652-3.

Cope, J. (2011). Entrepreneurial learning from failure: An interpretative phenomenological analysis. Journal of Business Venturing, 26 (6), 604-623. DOI: 10.1016/j.jbusvent.2010.06.002.

Fu, Z. (2005). Comparative Study on Mental Health between the Sitting Volleyball Athletes and the Average Disabled [J]. Journal of Jilin Institute of Physical Education, 2, 043.

Gao, H. \& Gao, P. (2007). A study on relationship between psychological health conditions and social support of men's sitting volleyball Athletes in China. 35 . 710069

Goodwin, D. L., Thurmeier, R., \& Gustafson, P. (2004). Reactions to the metaphors of disability: The mediating effects of physical activity. Adapted Physical Activity Quarterly, 21(4), 379-398.

Hays, R. D., Wells, K. B., Sherbourne, C. D., Rogers, W., \& Spritzer, K. (1995). Functioning and well-being outcomes of patients with depression compared with chronic general medical illnesses. Archives of general psychiatry, 52(1), 1119.

Ibrahim, A. A. L. (2010). The Impact of Weight Training on the Defensive Performances for the Sitting Volleyball Players (Amputees). World Journal of Sport Sciences, 3, 1146-1150.

Ibrahim, A. A. L. (2010). Effect of Physical Effort with Different Intensity on Some Blood Variables at Sitting Volleyball Players (Amputees). World Journal of Sport Sciences, 3, 1245-1249. 
Jespersen, E., \& McNamee, M. (2008). Philosophy, adapted physical activity and dis/ability. Sports Ethics and Philosophy, 2(2), 87-96. DOI: 10.1080/17511320802267672.

Katalin, K. (2008). Injury-and sport-specific training for sportsman with disabilitysitting volleyball players (Doctoral dissertation, Semmelweis University).

Koivula, N. (1999). Sport participation: Differences in motivation and actual participation due to gender typing. Journal of Sport Behaviour, 22, 360-380.

Kvale, S. (2006). Dominance through interviews and dialogues. Qualitative inquiry, 12(3), 480-500.

Larkin, M., Watts, S., \& Clifton, E. (2006). Giving voice and making sense in interpretative phenomenological analysis. Qualitative research in psychology, 3(2), 102-120.

Michalko, R., \& Titchkosky, T. (Eds.). (2009). Rethinking normalcy: A disability studies reader. Canadian Scholars' Press.

Toombs S. K. (1995). The lived experience of disability. Human Studies 18, 9-23.

Miller, T., Birch, M., Mauthner, M., \& Jessop, J. (Eds.). (2012). Ethics in qualitative research. Sage.

Mulhall, A. (2003). In the field: notes on observation in qualitative research. Journal of advanced nursing, 41(3), 306313.

Penninx, B. W., Leveille, S., Ferrucci, L., Van Eijk, J. T., \& Guralnik, J. M. (1999). Exploring the effect of depression on physical disability: longitudinal evidence from the established populations for epidemiologic studies of the elderly. American journal of public health, 89(9), 1346-1352.

Place, K., \& Hodge, S. R. (2001). Social inclusion of students with physical disabilities in general physical education:
A behavioral analysis. Adapted Physical Activity Quarterly, 18(4), 389-404.

Protić, M., \& Valkova, H. (2011) Psychosocial aspects of player's engagement to sitting volleyball. Coach, $1,1-1$.

Reid, G. (2003). Defining adapted physical activity. Adapted physical activity, 11-25.

Richard, M., Christina, M. F., Deborah, L. S., Rubio, N., \& Kennon, M. S. (1997). Intrinsic motivation and exercise adherence. Int J Sport Psychol, 28(4), 335-354.

Smith, J. A. (2004). Reflecting on the development of interpretative phenomenological analysis and its contribution to qualitative research in psychology. Qualitative research in psychology, 1(1), 39-54.

Smith, B., \& Sparkes, A. C. (2005). Men, sport, spinal cord injury, and narratives of hope. Social science \& medicine, 61(5), 1095-1105.

Smith, J. A., \& Osborn, M. (2007). Pain as an assault on the self: An interpretative phenomenological analysis of the psychological impact of chronic benign low back pain. Psychology and Health, 22(5), 517-534.

Tangen, S. \& Kudlacek, M. (2014). Extreme sport and reconstruction of identity in persons with spinal cord injuries. European Journal of Adapted Physical Activity, 7(2), 3-12.

Taub, D. E., \& Greer, K. R. (2000). Physical activity as a normalizing experience for school-age children with physical disabilities implications for legitimation of social identity and enhancement of social ties. Journal of Sport \& Social Issues, 24(4), 395-414.

Teixeira, P. J., Going, S. B., Houtkooper, L. B., Cussler, E. C., Metcalfe, L. L., Blew, R. M., \& Lohman, T. G. (2006). Exercise motivation, eating, and body image 
variables as predictors of weight control. Medicine and Science in Sports and Exercise, 38(1), 179.

Turner III, D. W. (2010). Qualitative interview design: A practical guide for novice investigators. The qualitative report, 15(3), 754-760.

Turner, R. J., \& Noh, S. (1988). Physical disability and depression: A longitudinal analysis. Journal of health and social behavior, 23-37.

Maanen, J. V. (1988). Tales of the field: On writing ethnography. Chicago Guides to Writing, Editing, and Publishing.

Vute, R. (1999). Scoring skills performances of the top international men's sitting volleyball teams. Gymnica, 2, 55-62.

Vute R. (2009). Teaching and coaching volleyball for the disabled, Foundation Course Handbook. ISBN 978-961-253035-8. 